Jasna Stojanović

Universidad de Belgrado

\title{
Del monje ávido de lectura al apuntador idealista: los Quijotes serbios a través de los siglos
}

Palabras clave: Don Quijote, recepción, literatura serbia, personaje

La historia de la recepción de Don Quijote en la literatura serbia dura aproximadamente 250 años. El primer autor que descubre la obra de Cervantes y la presenta a sus compatriotas es Dositej Obradović, el fundador de nuestra literatura moderna, gran viajero y ciudadano europeo avant la lettre. Desde entonces, la novela cervantina ha sido para los intelectuales serbios de varias épocas un libro de sabiduría y de filosofía y, en lo puramente literario, una fuente inagotable y modelo plurivalente de inspiración.

En esta ponencia, dejando de lado los numerosos y diversos ejemplos de la presencia cervantina/quijotesca y de su aclimatación en nuestras letras, nos proponemos enfocar algunas recreaciones del héroe cervantino en novelas creadas en los siglos XVIII, XIX y XX, tomadas como ejemplos típicos de un momento específico, pero también como muestras de la personalidad artística de sus respectivos autores. Asimismo, nuestro propósito es investigar de qué manera y hasta qué punto el legado cervantino ha sido creativamente transfigurado y qué características constantes de la personalidad de Don Quijote han resistido el paso del tiempo'.

Dositej Obradović, un espíritu ilustrado quien renunció a la vida monacal para dedicarse a estudiar, viajar, y organizar el sistema escolar en Serbia, plasma

$1 \quad$ Nos parece que este tipo de investigación puede abrir la puerta a fructíferas investigaciones de carácter comparativo entre varias literaturas del sureste europeo, que han compartido a través de la historia el mismo espacio cultural y tenido parecidas influencias culturales y literarias. Gracias a unos análisis paralelos de la recepción de Don Quijote se podrían establecer analogías o, por el contrario, diferencias significativas entre, por ejemplo, las literaturas serbia y eslovena, serbia y croata, etc. 
numerosos elementos del arte narrativo cervantino en su libro Vida y aventuras (Život i priključenija, I, 1783) (Stojanović, 2005: 17-33). Es una obra a medio camino entre autobiografía y novela en la que el autor narra su vida desde la infancia. Es considerada por Jovan Deretić como precursora de la novela realista serbia (Deretić, 1981: 192). Para nosotros, no hay duda alguna de que se trata de una novela quijotesca (Marthe Robert, 1967: 7), o, dicho con palabras de otro investigador, de un libro sobre «lectores adictos» (addicted readers, Stephen Gilman, 1989: 2).

De hecho, el protagonista, un novicio llamado Dimitrije, es un lector apasionado. Nos cuenta cómo, en vez de correr y de saltar con los demás niños, ya de pequeño dedicaba cada rato libre a la lectura, cómo «engullía y devoraba» las vidas de santos («gutao i proždirao»; Obradović, 1982: 97), y cómo se aprendía todo lo leído de memoria: «[...] cada vez que estaba en la iglesia, me ocultaba en el altar y agarraba unos cuentos valacos o consejas y me entretenía leyéndolos hasta el final de las Horas. A cualquiera que quería escucharme, le recitaba de la mañana basta la nocbe (cursiva J. S.) los cuentos de las vidas de santos»² (Obradović, 1982: 89; todos recordamos que Alonso Quijano se pasaba también las noches leyendo «de claro en claro» y los días «de turbio en turbio»). La lectura preferida del joven novicio eran las hagiografías, única materia novelesca de nuestra literatura de entonces, tan atractiva por sus rasgos fantásticos y maravillosos. Igual que ocurre con don Quijote, en la mente de Dimitrije empiezan a solaparse la realidad y la ficción, o, como confiesa él mismo, la cabeza se le llenó de «pensamientos varios, de opiniones y contradicciones» («svakojakih ponjatija, mnjenija i protivrečija»), y de una «confusión babilónica» («smuštenija vavilonskoga»).

Como su primo manchego, Dimitrije fantasea irse por el mundo para encontrar - no castillos, sino algún desierto o una cueva donde pasar el resto de su vida. Intenta escapar del monasterio dos veces, a escondidas y muy de mañana. Elige su nombre monacal inspirado por la vida de su modelo, en este caso ya no de un caballero de la estirpe de Amadís, sino de un caballero de Dios - San Demetrio de Tesalónica, cuya vida leyó apasionadamente. Obradović apunta:

[...] entre todas las vidas, preferí de lejos la de mi homónimo. La historia dice que, siendo niño de siete años, él también dejó a sus padres y se hizo monje [...]. Me gustó su nombre y

2 «[...] kad bih god bio u crkvi, sakrio bih se u oltar, dočepao bih se vlaškog kazanija iliti poučenija, pak bih čitao sve do savršenja crkovnoga pravila [...]. Ko bi me god hoteo slušati, kazivao bih mu od jutra do noći povesti iz prologa.» 
determiné, una vez tonsurado y habiendo dejado mi nombre de bautismo, elegir el suyo. Fue exactamente lo que hice ${ }^{3}$. (Obradović, 1982: 101)

En su libro cuenta además varios episodios humorísticos, resultado de su afán de imitar a los santos de la Iglesia:

Había leído en las hagiografías que hubo ermitaños que no ponían nada en la boca durante una semana entera, y otros incluso durante cuarenta días. Me esforzaba intentando alcanzar hasta el séptimo día, pero en vano; no aguantaba más de tres y el cuarto ya me tiritaban las rodillas, sentía un dolor estridente en el estómago y perdía la conciencia4 . (Obradović, 1982: 147)

En su libro Reflections on the Hero as Quixote, Alexander Welsh habla de «Quijotes adolescentes», refiriendóse a los protagonistas jóvenes de la literatura americana e inglesa del XIX (Scott, Dickens, Thackeray, etc). Son personajes con rasgos quijotescos que, sin embargo, van desapareciendo conforme los jóvenes van creciendo y entrando en el mundo adulto. Welsh no conocía a Dositej Obradović; no obstante, su autobiografía está ideada según la misma fórmula: los primeros indicios de la maduración de Dimitrije se notan cuando se da cuenta de la mala influencia de sus lecturas piadosas y cuando decide abandonar el monasterio, en busca de conocimientos nuevos. Su maduración espiritual es simbólica para la cultura y la historia serbias en general.

El siguiente Quijote aparece medio siglo más tarde, o sea en 1838, en la obra de Jovan Sterija Popović Roman sin novela (Roman bez romana). El clásico de la literatura serbia, poeta, dramaturgo y novelista, Sterija creó con su Roman sin novela una antinovela que permitió a nuestra literatura tomar un rumbo completamente nuevo, el paródico-humóristico. Roman sin novela es una imitación burlesca de la literatura idealista, serbia ante todo (obras de Milovan Vidaković y de sus epígonos), pero también extranjera.

3 «[...] osim sviju omili mi se žitije moga imenjaka. Piše se o njemu da i on, dete od sedam godina budući, ostavi roditelje i ode u kaludjere, i pročaja. Smili mi se ime ovo i odsudim da, kad se postrižem i moga na krštenju imena odrečem, da ću to ime izabrati. Tako sam i uradio.»

4 «Nahodio sam u žitijam da neki od pustinjaka po celih sedam dana, a neki po četrdeset, ništa ne bi u usta uložili. Silio sam se ne bih li i ja mogao do sedmog dna doterati, no zaludu; nisam mogao više nego do tri dni, jer u četvrti drktala bi mi kolena, čuvstvovao bih jaki bol u utrobi, i dolazio bih u nesvesticu.» 
El protagonista de Roman sin novela es un caballero cómico, apodado «nuevo don Quijote» y «nuevo Amadís» (aunque Sterija no se refiere al héroe de Rodríguez de Montalvo, sino al del alemán Wieland). El rasgo principal que le aproxima al viejo manchego es la pasión por la lectura. Roman, según dice su nombre (roman significa novela en serbio), era desde el nacimiento predestinado para las «historias románticas» («romantičeske povesti», es decir la ficción idealista), y hecho a ellas gracias al cura del lugar, quien se las suministraba con regularidad: «Traía a su querido pupilo [...] cualquier novela que podía encontrar y se las leía diciéndole que ésa era la mayor alegría para el hombre, así que Roman [...] se enamoró tanto de la lectura de los libros fantásticos que no podía separarse de ellos ni a la hora de comer»5 (Popović, 1982: 27). Ambos, don Quijote y Roman, tienen una imaginación fuera de lo común («poetičesko voobraženije»), así como un fuerte deseo de convertir la ficción en realidad. El personaje de Sterija tiene dos ídolos que pretende imitar: Velimir - prototipo del héroe sentimental, sacado de Velimir y Bosiljka (Velimir i Bosiljka) de Vidaković-, y Burjam - modelo del caballero valiente, de la novela Ljubomir en Elíseo /Ljubomir u Jelisijumu/-, también de Vidaković) (Flašar, 1982). Asimismo, el joven siente un afán pujante por recorrer mundo para buscar aventuras. Estableciendo una comparación cómica con los preparativos de Alonso Quijano (I, 1), Sterija cuenta cómo Roman, antes de salir, intenta valerse de un sable de madera y de un sombrero de papel multicolor («drvena sablja» $\mathrm{i}$ «klobuk od šarene artije»; Popović, 1982: 25):

Su vestimenta podría equipararse a la del caballero más insigne [...]. Los pantalones, de un azul inmaculado y hechos según la última moda, el jubón, llegándole casi hasta las rodillas y hermosamente bordado, el casco en la cabeza - todo indicaba que Roman era de alta alcurnia, y, como seña de caballero, llevaba botas son espuelas. Un caballo joven y excelente, que cada pachá pagaría 10.000 monedas, el sable afilado como un diente de serpiente, y a su lado derecho la alabarda y la lanza ${ }^{6}$. (Popović, 1982: 34).

5 «Sve romane, gdi god je naći mogao, donosio [...] svom ljubimom pitomcu, čitaše mu i slađaše mu da je tu najbolje za čoveka uveselenije, i - Roman, ionako sklonjen na to, tako se zaljubi u čitanje romantičeski knjiga da se ni u vreme ručka od nji rastaviti nije mogao.»

6 «Njegove aljine mogle bi najvećem gavaleru prkositi [...]. Čisto plavetne čakšire, po najnovijoj modi načinjene, preko koji skoro do kolena lepo izvezena dolama, na glavi kalpak pokazivaše da je Roman od velike kuće, i za znak da je riter imao je čizme s mamuzama. Konj mlad i prekrasan, za koga bi svaki paša 10.000 groša dao, sablja oštra kao zmija, na desnoj strani nadžak i koplje.» 
La verdad es que el caballo es una yegua, apodada «Rozinanta» (Rocinante, pronunciado a la alemana), y su dueño, a diferencia del manchego, un cobarde y un inútil, cuya única valentía consiste en - roncar fuerte: «Tumbado sobre la oreja derecha, junto a sus armas, intrépidamente echa a roncar» ${ }^{7}$, se burla Sterija (Popović, 1982: 34). Sus demás rasgos tampoco son muy caballerescos: es holgazán, soso, ingrato, cobarde y de poca moral. Lo demuestra cuando deja plantada a la hija del agá, Čimpeprič, quien le salvó la vida, enamorándose de él. En suma, Roman es exactamente opuesto al caballero leal y galán que pinta Cervantes en la figura de don Quijote.

En este libro humorístico, Sterija ridiculiza los esquemas narrativos de la ficción heroica y sentimental serbia (inspirándose en Cervantes, Sterne, Wieland, Rabener y Blumauer), proclamando que, en vez de esta literatura anticuada, ya era hora de escribir novelas según reglas más modernas.

Con el autor siguiente, ya nos adentramos en el período de la mayor popularidad de Don Quijote en nuestras tierras, el período romántico, que comienza en los años 60 del siglo XIX. Los héroes quijotescos se tiñen ahora de matices más serios e incluso trágicos, que revelan el cambio en la percepción del héroe cervantino, difundido por los románticos alemanes.

El novelista Jakov Ignjatović da vida a numerosos protagonistas siguiendo precisamente este modelo: crea individuos excéntricos que no encajan en la sociedad, unos incomprendidos y a veces rebeldes que, no obstante, son afables por naturaleza y amantes de la literatura. Pera Kirić, de la novela $E l$ novio eterno (Večiti mladoženja, 1878), es abiertamente comparado con don Quijote: es física y espiritualmente primo hermano del caballero manchego:

Era alto de figura. Derecho como un huso. El rostro alargado y extremadamente ovalado, enjuto y amarillento; los ojos negros, grandes, las cejas grandes, la frente larga; por delante bastante calvo; la mirada, altiva. Nada más verlo, diría uno: 'Es el mismo don Quijote'. Tanto se parecía a éste, o por lo menos a los retratos que de él hacían. Y lo más extraordinario es que tenía el mismísimo temperamento de don Quijote 8 . (Ignjatović, 1987: V, 261)

7 «On legne na desno uvo i junački pored svoga oružija zarče.»

8 «Stvora je bio povisokog. Prav kao trska. Lice uzano i jako ovalno, suvo, žućkasto; oči crne, velike, velike obrve, čelo veliko, pa spreda dosta ćelav, ma još mlad; pogled ponosit. Ko ga je prvi put vidio, odma' je morao reći: ,Ovo je isti Don-Kihot.' Tako je na ovog naličio, ili bar na sliku kako Don-Kihota malaju. I što je čudo, imao je i narav Don-Kihotovu.» 
Es un individuo original; vive solo, no tiene pareja y desatiende a su padre, a su hermano y al oficio familiar (el comercio). Tiene por única compañía a un criado, una especie de Sancho apenas esbozado. Sus rasgos más distinctivos son su fuerte imaginación y su comportamiento insólito: «[...] las ideas de Pera, sus planes, eran raros, extraordinarios, que a menudo hacían reír a la gente, pero uno tiene que admitir que eran originales»9 (Ignjatović, 1987: V, 261). Por dar un ejemplo, Pera decide construir una granja para curar caballos viejos y luego, una vez curados, venderlos; o este otro: después de morir su padre, insatisfecho con lo que ha heredado, determina serrar la casa familiar para dividirla en dos mitades, etc. El destino de Pera nos es contado con una mezcla de ironía y de compasión. Ignjatović ve a su personaje como a un desdichado con vanas ilusiones; siente lástima por él, porque todo lo que emprende está destinado a fracasar: «Así vive Pera. De verdad, como Sísifo. Pero igual no desiste. Empieza para tropezar enseguida; empieza otra vez, y otra vez tropieza, y siempre así. Vivía una vida deplorable $\gg^{10}$ (Ignjatović, 1987: V, 261). Como don Quijote, una vez mayor, Pera despierta de su locura («Pod starost [...] došao k sebi»; Ignjatović, 1987: V, 338).

Vasa Rešpekt (Vasa Rešpekt, 1875), otro personaje de Ignjatović, es un marginado que tampoco cuadra en la sociedad y que pasa buena parte de su vida en la cárcel. Tiene varias pasiones quijotescas, y la más destacada es la lectura. Vasa emplea las largas horas de encarcelamiento leyendo todo lo que le cae en las manos. Prefiere «las canciones heroicas serbias de los viejos 'florilegios'» («srpke junačke pesme iz nekih starih 'sobranija'»; Ignjatović, 1987: V, 41) y los cantares sobre los jaiduks (insurgentes serbios que luchaban contra los Otomanos). Se enfrasca tanto en la lectura que identifica la ficción con la realidad: «Creía que todo lo que había leído sobre los héroes había acontecido justo como él lo había leído, aunque pareciera poco probable: Kraljević Marko matando a los árabes, las hazañas de Strahin-ban, Vasa no hubiera permitido que pudiera ser de otra manera ${ }^{11}$ (Ignjatović, 1987: V, 41). Vasa es para su creador el prototipo del soldado perfecto. Es valiente y leal, apegado a ideales de libertad y de justicia, bondadoso y generoso con sus

9 Perine »misli, planovi bili čudnovati, izvanredni, da se mlogo puti njima svet smejao, al ${ }^{c}$ opet bili su originalni.»

10 «Tako živi Pera. Zaista Sizifov posao. I opet ne da si iz glave izbiti. Počne pa padne, pa opet počne pa padne; i sve tako. A pokraj toga živeo je čemerno.»

11 «Što je god čitao o junacima, sve je držao da se baš tako zbilo, mada je na nemogućnost naličilo. Kako seče Arape Kraljević Marko, junaštvo Strahinj-bana, - to Vasa ne bi dopustio da je moglo biti drukčije.» 
enemigos. Sin embargo, su carácter impetuoso e imprevisible hace que la gente le mire con recelo.

Otro primo de don Quijote podría ser Branko Orlić, protagonista de la primera novela de Ignjatović, Milan Narandžić (Milan Narandžić, 1860-1862). Es un romántico par excellence, un idealista que se desenvuelve con dificultad en la vida real. Branko es diferente a los demás: afable en el trato con la gente, ingenuo en las cosas de amor, tolerante. Es un personaje que tiene en su compañero, el materialista Milan Narandžić, a su antípoda. Encontramos en las obras de Ignjatović numerosos casos de parejas donde se contrastan, casi según el mismo esquema, el idealista y el materialista ${ }^{12}$ y que demuestran cómo la tradición ha ido simplificando la compleja dialéctica de las relaciones amo-escudero de la novela de Cervantes.

Cien años más tarde, un patrón muy parecido todavía sigue en pie a la hora de imaginar héroes quijotescos. En la novela de Ratomir Damjanović La versión de Sancho (Sančova verzija, 1999) aparece otro inadaptado, también idealista y amante de la literatura, sólo que los tiempos ya no son heroicos (como a mediados del siglo XIX, cuando los serbios glorificaban el espíritu guerrero de la nación), sino más bien desgraciados. Este personaje, llamado Stefan Krilović, aborrece la guerra. Vive en los años 90 del siglo XX, en la época de la desintegración de Yugoslavia, cuando el conflicto bélico trae dolor y devastación en toda la región.

Stefan es apuntador en el Teatro Nacional de Belgrado. Su apellido es simbólico (krilo significa «ala»), y su aspecto perfectamente reconocible: Es «[...] alto, de ojos vivos, pelo corto, rostro enjuto, encorvado e inclinado al lado izquierdo, con una camisa amplia de color claro, que le cuelga en los hombros como en un palo» ${ }^{13}$ (Damjanović, 1999: 10-11). Es un típico idealista que se consume por el arte, la belleza y la libertad. Se identifica con héroes de leyenda, de literatura y de vida; a ratos es Ícaro, Yoric o Hamlet, Colón o Van Gogh. No obstante, su identificación con don Quijote es la más fuerte: en el examen de entrada en la Escuela de Artes Dramáticas, pronuncia el monólogo del hidalgo cervantino ${ }^{14}$.

12 En la novela Čudan svet (1869) son Đoka Grozdić y Petar Kresović, en Trpen-spasen (18741875) Đoka Glađenović y Gavra Svilokosić, en Vasa Rešpekt Vasa y Steva Ognjan, en Večiti mladoženja Šamika y Pera.

$13 \ll[.$.$] visok, nemirnih očiju, kratko ošišan, ispijenog lica, povijen i nakrivljen na levu stranu,$ sa širokom svetlom košuljom što na njemu visi kao na drvenoj pritki.»

14 Sin embargo, Stefan posee a la vez rasgos quijotescos y sanchescos; por el lado prosaico, banal, de su existencia, es Sancho: »Los dos viven vidas separadas: al primero le ilusiona la 
Los caminos de La Mancha que surca Stefan son en realidad las olas de un océano inventado. El joven tiene un caballo imaginado que en tierra se llama Rocinante, y en el agua Santa María (como la carabela de Colón). Es más, en su casa ha construido «un cachivache que se parece a un barco». Su mapa náutico, dibujado por su propia mano, registra islas que llevan nombres de escritores, pintores y descubridores: Poe, Vincent, Sézanne, Camus, Fiodor, Jozef K., Blake. En consecuencia, su historia es una historia de viajes y de aventuras, parecida a la de don Quijote; Stefan está en busca de su orilla, en busca del sentido de la vida. Detesta la dura realidad que le rodea e intenta evadirse de ella como sea. Por desgracia, sus «magos» no son imaginarios ni bientintencionados (como el párroco, el barbero o el bachiller Carrasco): se trata de los nacionalistas que propagan el odio y de la policía militar que envía a los muchachos al frente contra su voluntad: «Ellos quieren hacer la guerra. Yo, lo único que puedo hacer, es cantar cantos guerreros, interpretarlos como escenas teatrales [...]. Pero hacer la guerra - nunca» ${ }^{15}$ (Damjanović, 1999: 201). Stefan intenta huir, primero refugiándose en el barco construido en su habitación, luego en el parque zoológico, en Nueva York y, finalmente, en la droga. Termina trágicamente.

Concluyendo, podemos deducir que en las letras serbias el modelo del héroe quijotesco se sigue utilizando desde finales del siglo XVIII hasta nuestros días. Resulta que en las novelas analizadas los rasgos preferidos de su carácter, por supuesto preformulados, han sido: 1) el amor por la lectura, 2) el deseo de convertir lo leído en realidad, 3) la inadaptación al entorno, 4) el idealismo (cualidad desarrollada especialmente por los románticos).

Cada uno de los Quijotes analizados refleja una época de nuestra literatura y su maduración a través del tiempo. Según hemos visto, la novela cervantina y su protagonista han servido de base para idear la historia de Dimitrije, novicio ávido de vidas de santos en el siglo XVIII (Ilustración), del caballero burlesco Roman a principios del XIX (Prerromanticismo), de varios inadaptados trágicos en la segunda mitad de la misma centuria (Pera, Vasa, Branko Romanticismo), así como de un pacifista idealista a finales del segundo milenio (Stefan - Literatura moderna). Gracias a su carácter abierto y a su fuerza

idea de ser actor y está perdidamente enamorado de la actriz Beatriz, mientras su otro 'yo', preocupado más bien por su estómago y su comodidad, pasa los días en una casita del barrio belgradense de Dorćol, en brazos de Dulci, la gordita ardiente.» De ahí el título de la novela. (Stojanović 2008: 712)

15 «Oni hoće da ratuju. Ja mogu samo da opevam ratničke igre, da ih odigram kao glumačku scenu [...], ali da ratujem - nikada.» 
poética, el caballero cervantino, símbolo universal, ha servido y sirve todavía de matriz válida para la más variada gama de protagonistas y de narraciones.

\section{Bibliografía}

Damjanović, R. (1999): Sančova verzija. Belgrado: SKZ.

Deretić, J. (1981): Istorija srpske književnosti. Belgrado: Nolit.

Flašar, M. (1982): «Filološke i književno-istorijske beleške». En: Jovan Sterija Popović: Roman bez romana. Belgrado: Nolit, 115-174.

Gilman, S. (1989): The Novel according to Cervantes. Berkeley: University of California Press.

Ignjatović, J. (1987): Odabrana dela, 1. Novi Sad-Priština: Matica srpskaJedinstvo.

Obradović, D. (1981): Život i priključenija. Pismo Haralampiju. Belgrado: Nolit. Popović, J. S. (1982): Roman bez romana. Belgrado: Nolit.

Robert, M. (1967): L’Ancien et le Nouveau. De 'Don Quichotte' à Kafka. París: Payot.

Stojanović, J. (2005): Servantes u srpskoj književnosti. Belgrado: ZUNS.

Stojanović, J. (2008): «El conflicto balcánico en una novela de corte cervantino: La versión de Sancho del escritor serbio Ratomir Damjanović». En: Alexia Dotras Bravo et al. (eds.), Tus obras los rincones de la tierra descubren. Madrid-Alcalá de Henares: Asociación de Cervantistas-Centro de Estudios Cervantinos, 709-718.

Welsh, A. (1981): «Adolescent Heroes». En: Reflections on the Hero as Quixote. Princeton: Princeton University Press. 
Jasna Stojanović

University of Belgrade

\section{From a reading devoted monk to an idealist prompter: the Serbian Quixotes across the centuries}

Keywords: Don Quixote, reception, Serbian literature, character

In this paper we analyze the characters of several Serbian novels published from the Enlightenment to the present day, whose main characters show obvious resemblances with Cervantes' Don Quixote: Dositej Obradović's Život i priključenija (1783), Jovan Sterija Popović's Roman bez romana (1838), various novels of Jakov Ignjatović (Večiti mladoženja, 1878; Vasa Rešpekt, 1875; Milan Narandžić, 1860-1862), and Sančova verzija by Ratomir Damjanović (1999). We analyze their personalities, pointing out the similarities with their model and then exploring the differences or particularities emanating from either the author's style, the period of its creation and/or the poetics of the Serbian literature. Our goal is to investigate the manner and the level in which the Cervantine legacy has been creatively transformed and what constant characteristics of the personality of Don Quixote have resisted the passage of time. 
Jasna Stojanović

Univerza v Beogradu

\section{Od duhovnika, željnega branja, do idealističnega šepetalca: srbski don Kihoti skozi stoletja}

Ključne besede: don Kihot, recepcija, srbska književnost, literarni lik

V prispevku avtorica razčlenjuje več srbskih romanov od razsvetljenstva do današnjih dni, katerih glavni junaki kažejo očitne podobnosti z glavnim likom Cervantesovega romana Veleumni plemič don Kibot iz Manče. Gre za dela Dositeja Obradovića Život i priključenija (1783), Roman bez romana Jovana Sterije Popovića (1838), za več romanov Jakova Ignjatovića (Večiti mladoženja, 1878; Vasa Rešpekt, 1875; Milan Narandžić, 1860-1862) in za delo Sančova verzija Ratomirja Damjanovića (1999). Avtorica razčlenjuje njihovo osebnost tako, da najprej izpostavi podobnosti s Cervantesovim junakom in nato razišče razlike ali posebnosti, ki izhajajo iz pisateljevega sloga, časa nastanka (18., 19. in 20. stoletje) in/ali poetike srbske nacionalne književnosti. Namen članka je raziskati, kako in v kakšni meri je bila Cervantesova zapuščina v srbski književnosti ustvarjalno preoblikovana ter katere značilnosti don Kihotove osebnosti so kljubovale času. 